\title{
KINETIC MODELING ON AMIDE HYDROLYSIS, DRUG RELEASE AND MUCOSAL PERMEATION OF INDOMETHACIN IN THE COMPOSITION OF SELECTED SEMISOLID VEHICLES
}

\author{
Nadezhda A. Ivanova ${ }^{1}$, Tsvetelina S. Stefanova ${ }^{2}$, Ivelin R. Iliev ${ }^{2}$, Georgi S. \\ Stoyanov $^{3,4}$, Kameliya Zh. Bratoeva ${ }^{5}$ \\ 1) Department of Pharmaceutical Technologies, Faculty of Pharmacy, Medical \\ University, Varna, Bulgaria \\ 2) Students at Faculty of Pharmacy, Medical University, Varna, Bulgaria \\ 3) Department of General and Clinical Pathology, Forensic Medicine and \\ Deontology, Faculty of Medicine, Medical University, Varna, Bulgaria \\ 4) Department of Anatomy and Cell Biology, Faculty of Medicine, Medical \\ University, Varna, Bulgaria \\ 5) Department of Physiology and Pathophysiology, Division of Pathophysiology, \\ Faculty of Medicine, Medical University, Varna, Bulgaria.
}

\begin{abstract}
The present study aims to reveal the role of a semisolid vehicle in the composition of Indomethacin dosage forms for their physical and chemical stability, in vitro and ex vivo behavior. Three types of hydrogels and emulgels were prepared with gelling agents Methylcellulose 2\%, Poloxamer $40720 \%$ and Carbomer 940 1\%. Each preparation was observed for physical and chemical stability at $5^{\circ} \mathrm{C}$ and $25^{\circ} \mathrm{C}$ within 3 months. Test formulations, along with USP standard Indomethacin gel and combined marked product Indextol,were subjected to in vitro drug release test and $e x$ vivo permeation study, using porcine intestinal mucosa on Franz diffusion cell. A hypothesis was built to predict steadystate plasma concentration $\left(\mathrm{C}_{\mathrm{ss}}\right)$ of Indomethacin for each formulation following mucosal administration. Results revealed sustained chemical stability of all emulgels for the period observed and significantly lower chemical stability of the corresponding hydrogels. Methylcellulose hydrogel (at both temperatures) and emulgel (at $25^{\circ} \mathrm{C}$ ) showed signs of phase separation, while all other formulations kept their physical appearance for the duration of the study. Methylcellulose emulgel along with Poloxamer 407 hydrogel showed highest cumulative drug release in 12 hours (58.01\% and $55.00 \%$, respectively). Same formulations exhibited also highest drug permeation rate $\left(\mathrm{J}_{\mathrm{ss}}\right)$ through mucosa $\left(10.55 \mu \mathrm{g} . \mathrm{cm}^{-2} \cdot \mathrm{h}^{-1}\right.$ and $13.20 \mu \mathrm{g} . \mathrm{cm}^{-2} \cdot \mathrm{h}^{-1}$, respectively) and highest predicted value of plasma concentration $\left(\mathrm{C}_{\mathrm{ss}}\right.$ up to $100.49 \mu \mathrm{g} . \mathrm{l}^{-1}$ and $125.71 \mu \mathrm{g} . \mathrm{l}^{-1}$, respectively), whereas highest drug deposition in mucosal tissue was detected for Poloxamer 407 emulgel $\left(2.1 \mathrm{mg} \cdot \mathrm{cm}^{-3}\right)$.
\end{abstract}

Keywords: Indomethacin emulgels, chemical stability, physical stability, drug release, kinetic modeling, ex vivo permeation

\section{INTRODUCTION}

Indomethacin is a non-steroidal anti-inflammatory drug used for the treatment of rheumatoid arthritis, gouty arthritis, bursitis, tendinitis and many other inflammatory conditions [1-13]. Although very potent and effective, Indomethacin has some considerable flaws. Its use in oral dosage forms is limited due to a wide range of gastrointestinal adverse effects, from mild dyspepsia to severe gastropathy and bleeding [4-7].

Indomethacin belongs to class II of the biopharmaceutical classification system (BSC), thus possesses high permeability, but poor water solubility [11-13]. Chemically unstable in an aqueous environment, it undergoes amide hydrolysis, which leads to loss of activity and increased toxicity [8-10]. The problems above are a challenge when it comes to formulation of Indomethacin dosage forms. Therefore innovative drug delivery systems and alternative routes of administration (rectal, nasal, buccal, dermal, etc.) are constantly sought. Sometimes it is convenient to approach these application sites via semisolid dosage forms such as gels, creams, ointments, and pastes. Due to the high water content in such dosage forms, they need to be observed for chemical degradation rate of Indomethacin, and, if they consist of multiphase vehicles, their physical stability should also be a consideration.

It is questionable and in our interest to find, whether the use of emulgels instead of hydrogels will improve stability of Indomethacin in this type of semi-solid formulations and whether such approach will affect the dosage forms' drug release and permeation potency following mucosal administration.

Oil in water $(\mathrm{o} / \mathrm{w})$ emulsions are well known to improve the bioavailability of active pharmaceutical ingredients (APIs) with low water solubility, as well as to increase 
chemical stability by limiting the contact of the drug with the water phase. However, as Indomethacin is very slightly soluble in most of mineral and triglyceride oils, thistype of dispersions are not always possible or suitable in their conventional form [3-7]. Several studies report formulation of Indomethacin emulsions by dissolving the drug in polar cosolvent, followed by addition of water to obtain dispersion, and only then emulsifying oil to increase the viscosity of the system [5-7]. It was our objective to find whether such unusually formulated emulsion would favor physicochemical and therapeutical properties of Indomethacin gel dosage forms if used as a mediator for drug inclusion.

\section{MATERIALS AND METHODS}

\section{Materials}

Indomethacin substance was a gift from Sofarma pharmaceuticals, Poloxamer 407 (Lutrol F-127) was a gift from BASF Germany, Indextol was supplied by a local pharmacy, other materials were provided from: Carbomer 940 - Fagron Hellas, Greece, Methylcellulose high viscosity (Metolose 90SH - 30000) - Synthapharm Ges. F. Pharmachemi., Germany Liquid paraffin - Himtex Ltd Bulgaria, Polysorbate, Sorbitan monooleate and Macrogol 400 - Panreac, Spain, Ethanol absolute $99.5 \%$ - Fisher Chemical, Sodium hydroxide, di-Sodium hydrogen phosphate, Potassium dihydrogen phosphate, Sodium chloride - Thermo Fisher Scientific, 0.22 $\mu \mathrm{m}$ pore size PES syringe filter - Filters Fioroni, Spain.

\section{Methods}

\section{Analytical procedure}

UV spectrophotometric method was chosen for Indomethacin assay. Stock solutions of Indomethacin (80 mg. $\mathrm{l}^{-1}$ ) in phosphate buffer saline (PBS) 7.4 and ethanol absolute were prepared and scanned on UV/Vis spectrophotometer. Absorption maxima was found at a wavelength of $319 \mathrm{~nm}$. Calibration curves were obtained within the concentration range of 4-80 mg. $1^{-1}$. All measurements were carried out onUV/Vis Spectrophotometer, (Reileight UV-9200, China).

Indomethacin stability in PBS 7.4 solution at room temperature $\left(25 \pm 0.5^{\circ} \mathrm{C}\right)$

Indomethacin's chemical instability due to amide hydrolysis is well known and studied [8-10]. The decomposition rate and kinetics in several semi-solid models and in stock solution (PBS 7.4) were assessed. The stock solution was stored in tempered room at $25 \pm 0.5^{\circ} \mathrm{C}$, protected from light, during the time of the study and samples were analyzed for drug content at fixed time intervals. Drug decomposition kinetics and rate constant of the degradation process were determined.

\section{Preparation of Indomethacin 1\% gels}

Three commonly used gelling agents for the preparation of pharmaceutical hydrogels and emulgels were selected - Methylcellulose high viscosity 2\%, Carbomer $9401 \%$ and Poloxamer 407 20\%. This attempt resulted in a total of six test formulation, shown in Table 1.

Table 1. Indomethacin test formulations

\begin{tabular}{|c|c|c|c|c|c|c|}
\hline Formulation code & IG1 & IG2 & IG3 & IG4 & IG5 & IG6 \\
\hline Methylcellulose, $\%$ & 2 & 2 & - & - & - & - \\
\hline Poloxamer 407, \% & - & - & 20 & 20 & - & - \\
\hline Carbomer $940, \%$ & - & - & - & - & 1 & 1 \\
\hline Indomethacin, $\%$ & 1 & 1 & 1 & 1 & 1 & 1 \\
\hline Purified water for gelation, $\%$ & 77 & 48 & 59 & 30 & 78 & 49 \\
\hline Purified water for $\mathrm{o} / \mathrm{w}$ emulsion, $\%$ & - & 20 & - & 20 & - & 20 \\
\hline Macrogol $400, \%$ & 15 & 15 & 15 & 15 & 15 & 15 \\
\hline Ethanol absolute, \% & 5 & 5 & 5 & 5 & 5 & 5 \\
\hline Polysorbate $80, \%$ & - & 0.85 & - & 0.85 & - & 0.85 \\
\hline Sorbitan monooleate, $\%$ & - & 0.65 & - & 0.65 & - & 0.65 \\
\hline $\mathrm{NaOH} 10 \%$ solution & - & - & - & - & q.s. & q.s. \\
\hline Liquid paraffin, $\%$ & - & 7.5 & - & 7.5 & - & 7.5 \\
\hline
\end{tabular}

All hydrogel bases were prepared in prior with the aid of the gelling agent and the water for gelation as follows: Methylcellulose was added to hot water $\left(90^{\circ} \mathrm{C}\right)$ under continuous stirring to obtain homogeneous dispersion and then left overnight to dissolve in refrigerator at $5^{\circ} \mathrm{C}$; Poloxamer 407 granules were added to the water at room temperature and left overnight to dissolve in refrigerator at $5^{\circ} \mathrm{C}$; Carbomer 940 was initially dispersed in small quantity of water in a mortar, then slowly diluted with the rest of the water for gelation and finally adjusted to $\mathrm{pH}$ 7-7.5 with the aid of sodium hydroxide $10 \%$ solution to obtain clear gel.

Preparation of Indomethacin hydrogels: Indomethacin was dissolved in a mixture of Macrogol 400 and Ethanol absolute under continuous stirring and short heating up to $40^{\circ} \mathrm{C}$ (for 2-3 minutes). The drug solution was then added in small portions to the corresponding gel base.

Preparation of Indomethacin emulgels: Indomethacin was found to be insoluble in the desired concentration in paraffin, castor, sunflower, linseed, and silicon oil. There fore emulsions were prepared as follows: Indomethacin was dissolved in a mixture of Macrogol 400 and Ethanol absolute as described above and water for emulsion was dropwise added to form a fine dispersion. Polysorbate 80 was dissolved in the so prepared "water" phase, whereas Sorbitan monooleate was dissolved in the liquid paraffin. Both phases were heated up to $70^{\circ} \mathrm{C}$ andemulsified under continuous stirring for 10 minutes. After cooling down, the emulsion was mixed gradually with the corresponding gel base to obtain emulgel.

Indomethacin topical gel 1\% USP standard was also prepared for reference, following the instructions of the US 
Pharmacopeia. Shortly, Indomethacin (1\%) was initially dissolved in Ethanol 95\% (55\%), the solution was then transferred in a mortar and homogenized with Carbomer 940 (2\%). Purified water $(10 \%)$ was dripped to the dispersion, and a sufficient quantity of Ethanol $95 \%$ was finally added to $100 \%$.

No preservatives were added to the test formulations in order not to interfere with the drug analysis.

Samples from each formulation were stored at $25^{\circ} \mathrm{C}$ and $5^{\circ} \mathrm{C}$, protected from light.

\section{Physical stability test}

All samples at both temperatures $\left(5\right.$ and $\left.25^{\circ} \mathrm{C}\right)$ were photographed and observed for the following signs of physical instability: change in color or odor, change in consistency, phase separation, and syneresis.

\section{Chemical stability test}

Samples at both temperatures $\left(5\right.$ and $\left.25^{\circ} \mathrm{C}\right)$ were analyzed for drug content at day 1, 30, 60 and 90. Quantity of $0.100 \mathrm{~g}$ of each formulation was accurately weighed in $25.0 \mathrm{ml}$ volumetric flask. Sufficient quantity of PBS 7.4 was added and homogenized with the gel until obtaining a uniform dispersion. Thereafter, the volume was adjusted up to the mark with PBS 7.4 and homogenized well once again. As a result, theoretical Indomethacin concentration of 40 mg. $1^{-1}$ was acquired ${ }^{1}$. The dispersion was filtered through $0.22 \mu \mathrm{m}$ pore size PES syringe filter and analyzed spectrophotometrically at $\lambda=319$. Actual drug content at time $t\left(\mathrm{a}_{t}\right.$, mg. $\mathrm{l}^{-1}$ ) was presented as a percentage from the initial (theoretical) concentration, using the formula: $\mathrm{a}_{t} \cdot 100 / 40$

Drug decomposition kinetics and rate constants of the hydrolysis process in all hydrogel- and emulgel models were determined.

\section{Prediction of shelf life}

Based on drug content analysis during storage, prediction of shelf life for the most promising test gels was made, using the relation:

Shelf life $=\mathrm{T}_{90 \%}$

Where $\mathrm{T} 90 \%$ is the time for which Indomethacin content in gels drops to $90 \%$.

\section{In vitro drug release study \\ Procedure}

Drug release studies were carried out on Franz diffusion cell through cellulose acetate membrane. All test formulations having showed satisfactory physical stability were subjected to the test along with USP standard Indomethacin gel and marketed oromucosal paste Indextol as reference. The cell possessed exposed membrane surface area of $0.98 \mathrm{~cm}^{2}$ and receptor volume of $8.0 \mathrm{ml}$. Receptor volume was filled almost to the top with PBS 7.4, and the cell was tempered at $37 \pm 0.5^{\circ} \mathrm{C}$ with the aid of a circulating thermostat. The membrane was then carefully placed and the cap was fixed with Parafilm ${ }^{\circledR}$ and with the clamp. Sample of the test formulation with a mass of $0.200 \mathrm{~g}$ was carefully applied on the surface of the cellulose membrane through the open cell cap, adhesion to the membrane was ensured with the aid of a tiny piston, and finally the open cell cap was covered with Parafilm ${ }^{\circledR}$ to prevent evaporation from the dosage form and the release media during the test ${ }^{2}$. Receptor volume was adjusted to the top using the sampling port, and stirring of $300 \mathrm{rpm}$ was initialized. Sufficient volume from the release media was withdrawn at fixed time intervals, analyzed spectrophotometrically for drug released and then returned to the cell receptor volume ${ }^{3}$. Data for cumulative percentage drug released $(\mathrm{CDR} \%)$ was collected within 12 hours.

\section{Drug release kinetics}

Based on the drug release data obtained $\left(\mathrm{M}_{t} / \mathrm{M}_{\propto} \leq 0,6\right)$, release kinetics and kinetic constants were determined with the aid of Excel 2013. Linear regression analyses were made for zero-order (1), first-order (2), Higuchi (3) and KorsmeyerPeppas (4) models [6, 14-16]:

(1) $M_{t} / M_{\propto}=k_{0 . t}$

(2) $\quad M_{r} / M_{\propto}=e^{-k 1 t}$ or linear $\ln M_{r}=\ln M_{\propto}-k . t$

(3) $\quad M_{t} / M_{\propto}=k_{2} . t^{0.5}$

(4) $\quad M_{t} / M_{\propto}=k_{3} . t^{n}$ or linear $\log M_{t}=\log M_{\propto}+n . \log$ $t+\log k_{3}$

Where $\mathrm{M}_{t}$ is the amount of drug released at time $t$, $\mathrm{M}_{r}$ is the amount of drug unreleased at time $t, \mathrm{M}_{\propto}$ is the total amount of drug applied with the dosage form, $\mathbf{M}_{t} / \mathrm{M}_{\propto}$ represents the drug released fraction, $\mathrm{M}_{r} / \mathrm{M}_{\propto}$ - the drug unreleased fraction, $\mathrm{k}_{0}, \mathrm{k}_{1}, \mathrm{k}_{2}$, and $\mathrm{k}_{3}$ are kinetic constants, and $\mathrm{n}$ is the release exponent. $M_{t} / M_{\propto}$ was used as percentage $(\%)$ cumulative drug released (or unreleased) and time was presented as minutes, so that the kinetic constants acquired the following measures: zero order constant $\mathrm{k}_{0}$ [\%.min ${ }^{-}$ $\left.{ }^{1}\right]$, first order constant $\mathrm{k}_{1}\left[\mathrm{~min}^{-1}\right]$, Higuchi kinetic constant $\mathrm{k}_{2}\left[\% \cdot \min ^{-0.5}\right]$ and Korsmeyer-Peppas constant $\mathrm{k}_{2}\left[\% \cdot \mathrm{min}^{-\mathrm{n}}\right]$.

Indomethacin solubility in PBS 7.4

During drug release tests, the requirement for "sink" conditions should be a consideration, especially when dealing with poor water-soluble substances like Indomethacin. Indomethacin solubility was studied before the drug release test in the same release media - PBS 7.4.

Indomethacin was added in excess to $10.0 \mathrm{ml}$ PBS 74 and kept under stirring for 24 hours in a tempered room at $25 \pm 0.5^{\circ} \mathrm{C}$. Sample from the supernatant was withdrawn, filtered through $0.22 \mu \mathrm{m}$ pore size PES syringe filter and after proper dilution analyzed spectrophotometrically. Next, the system was warmed up to $37^{\circ} \mathrm{C}$ and kept under stirring for another 24 hours. Drug concentration in the supernatant was analyzed analogically after proper dilutions were made with preheated to the same temperature PBS 7.4. Drug solubility based on drug concentration in the supernatant was determined as mean of three replicates.

\section{Indomethacin stability in PBS 7.4 at $37 \pm 0.5^{\circ} \mathrm{C}$}

Accurate drug release studies require temperature close to the physiological in the site of application, which in the case of mucosal administration is close to $37^{\circ} \mathrm{C}$. However, such elevated temperature (compared to standard room temperature) usually leads to an increase in the drug degradation rate and thus could be a potential source of an error during the drug release analysis. With other words, the drug could be released in the receptor media, but due to degradation, left unestablished. Therefore, we estimated the drug degradation rate of Indomethacin in PBS 7.4 at $37 \pm 0.5^{\circ} \mathrm{C}$ 
for the duration of the drug release study (12 hours). The results obtained we applied as a correction (maximum possible deviation) on the CDR\% data.

\section{Ex vivo permeation study}

Mucosal tissue preparation

A fresh specimen of a pig rectum measuring $10 \mathrm{~cm}$ in length was harvested, cut longitudinally to open the lumen and observed for any abnormalities, thoroughly washed in PBS 7.4 and frozen at $-80^{\circ} \mathrm{C}$. Following a 24-hour freezing time at $-80^{\circ} \mathrm{C}$, the rectum was left to defrost at room temperature and placed in cooled PBS $7.4\left(15^{\circ} \mathrm{C}\right)$.

The specimen was manually dissected under a stereomicroscope with a magnification of $15 \mathrm{x}$ with cold steel instruments. The instruments used were a sharp-tipped dissection forceps, for grasping the lamina propria, tela submucosa, tela muscularis, and the adventitia and a DeBakey forceps for grasping and atraumatic mechanical peeling of the mucosa. After the dissection, the separated mucosa was further observed under the same magnification of the stereomicroscope for removal of any attached blood vessels left and remaining non-mucosal tissue. The separated mucosa was measured to be $0.16 \pm 0.01 \mathrm{~cm}$ thick. After being thoroughly washed in PBS 7.4, the mucosal tissue was cut in sections measuring $2 \times 2 \mathrm{~cm}$ with a cold steel scalpel. The prepared sections were placed in cooled PBS 7.4 [17].

\section{Procedure}

Ex vivo permeation study was performed on Franz diffusion cell following the same procedure as described above (In vitro drug release study), but using porcine intestinal mucosa as a membrane. The mucosa was placed so that the smooth mucosal surface faces the donor compartment. $\mathrm{Cu}-$ mulative drug permeated (CDP) was detected at 2-, 4-, 8-, 12- and 24 hour of the experiment.

Data analysis

For this analysis, we applied on the mucosa quantity of each dosage form much higher than the usual for this surface area so that the concentration gradient does not change substantially (more than 10\%) for the duration of the study. This allowed us, with certain approximation, to apply the simplified version of Fick's first low for steady state diffusion $\left(\mathrm{J}_{\mathrm{ss}}=\mathrm{K}_{\mathrm{p}}\right.$. $\boldsymbol{\Delta C}$, where $\mathrm{J}_{\mathrm{ss}}$ is the steady-state flux, $\mathrm{K}_{\mathrm{p}}$ is the permeability coefficient, and $\boldsymbol{\Delta} \mathrm{C}$ is the concentration gradient representing the difference between the drug concentration in the donor compartment $-\mathrm{C}_{\mathrm{d}}$ and the receptor compartment $-\mathrm{C}_{\mathrm{r}}$ ) in order to analyze the results. Permeation parameters were obtained from the CDP versus time plots. The steady state flux $\left(\mathrm{J}_{\mathrm{ss}}\right)$ was calculated from the slope of the linear regression and presented as $\mu \mathrm{g} . \mathrm{cm}^{-2} \cdot \mathrm{h}^{-1}$. Linear regression coefficient was also applied to the results. The permeability coefficient $\left(\mathrm{K}_{\mathrm{p}}\right)$ was calculated as $\mathrm{K}_{\mathrm{p}}=\mathrm{J}_{\mathrm{ss}} / \mathbf{\Delta C}$, assuming that the concentration gradient $\left(\boldsymbol{\Delta C}=\mathrm{C}_{d}-\mathrm{C}_{\mathrm{r}}\right)$ is constant and thus $\boldsymbol{\Delta} \mathrm{C}$ can be replaced with initial drug concentration in the dosage form $\left(\mathrm{C}_{\mathrm{d}}\right)\left[\mu \mathrm{g} . \mathrm{cm}^{-3}\right]\left(\boldsymbol{\Delta C} \approx \mathrm{C}_{\mathrm{d}}\right.$, and $\mathrm{K}_{\mathrm{p}} \approx \mathrm{J}_{\mathrm{ss}} / \mathrm{C}_{\mathrm{d}}$ ). Knowing the approximate thickness of our mucosal tissue $(0,16 \mathrm{~cm})$, we substituted in the equation $\mathrm{K}_{\mathrm{p}}=$ $\mathrm{P} . \mathrm{D} / \mathrm{h}$, where $\mathrm{P}$ is the partition coefficient of the drug into the barrier, $\mathrm{D}$ is the diffusion coefficient and $\mathrm{h}$ is the thickness of the membrane. Thus, P.D $=\mathrm{K}_{\mathrm{p}}$.h was presented next on the results as $\mathrm{cm}^{2} \cdot \mathrm{h}^{-1}$. The lag time $\left(\mathrm{T}_{\mathrm{L}}\right)$ represents the time necessary to establish steady state diffusion after the initial contact of the dosage form with the mucosal tissue. $T_{L}$ was calculated for $y=0$ using the linear regression of the flux [4,6, 18-20].

Prediction for steady-state plasma concentration $\left(C_{s s}\right)$ of Indomethacin

Each formulation is expected to possess a different potential for systemic absorption of Indomethacin after mucosal application, therefore, based on the data analysis we applied a theoretical hypothesis with the following assumptions:

1. The dosage form is applied rectally;

2. Absorption area (S) is $40 \mathrm{~cm}^{2}[21]^{4}$

3. The patient is $70 \mathrm{~kg}$

4. Indomethacin plasma clearance $\left(C_{L}\right)$ is $0.06-0.015$ $\mathrm{L} . \mathrm{kg}^{-1} \cdot \mathrm{h}^{-1}[22,23]$

The steady-state plasma concentration $\left(\mathrm{C}_{\mathrm{ss}}\right)$ was calculated using the equation $\mathrm{C}_{\mathrm{ss}}=\mathrm{J}_{\mathrm{ss}} . \mathrm{S} / \mathrm{C}_{\mathrm{L}}$, where $\mathrm{J}_{\mathrm{ss}}$ is the steady-state flux, $S$ is the absorption area, and $C_{L}$ is the plasma clearance [17].

Drug deposition study

Deposition of Indomethacin in the mucosal tissue after 24 hours since application was determined by two methods:

Method I: At the end of the drug permeation test, the mucosal tissue was carefully detached from the receptor compartment's surface, washed thoroughly with PBS 7.4, immersed in $10.0 \mathrm{ml}$ Ethanol absolute and shattered in small pieces with the aid of seizures and tweezers. So prepared, the mucosa was kept in Ethanol at room temperature, protected from light, for 24 hours. Ethanol was then decanted in $25.0 \mathrm{ml}$ volumetric flask and replaced with fresh portion solvent $(4-5 \mathrm{ml})$. This procedure was repeated every 2 hours several times until the final volume of $25.0 \mathrm{ml}$ was obtained in the volumetric flask. The ethanol extract was filtered through $0.22 \mu \mathrm{m}$ pore size PES syringe filter and analyzed spectrophotometrically for Indomethacin content. A limitation of this method we consider the impossibility of $100 \%$ extraction of Indomethacin from the mucosa and possible interference of extracted membrane lipids on the assay.

Method II: At the end of the drug permeation study, all cell parts having had contact with the test dosage form, including the mucosal tissue, were thoroughly washed with PBS 7.4 in a $250.0 \mathrm{ml}$ beaker and then removed from the vessel. The mixture was well homogenized as remaining gel parts were visible and then transferred to $25.0 \mathrm{ml}$ volumetric flask. Volume was adjusted up to the mark with PBS 7.4, filtered through $0.22 \mu \mathrm{m}$ pore size PES syringe filter and analyzed spectrophotometrically for drug remained unreleased. Drug deposition in mucosa was calculated as:

\section{Deposition in mucosa = total amount of drug applied - drug released after 24 hours - drug unreleased}

A limitation of this method we consider the higher risk of an error, the lack of a double check/control mechanism over the results.

For both methods, drug deposition was presented as $\mathrm{mg} \cdot \mathrm{cm}^{-3}$, considering the mucosal volume of the tissue to 
be $0,157 \mathrm{~cm}^{3}$ (exposed area $0.98 \mathrm{~cm}^{2} \mathrm{x}$ thickness $0.16 \mathrm{~cm}=$ $0.157 \mathrm{~cm}^{3}$ volume).

\section{RESULTS \\ Indomethacin stability in PBS 7.4 solution at room} temperature $\left(25 \pm 0.5^{\circ} \mathrm{C}\right)$

Indomethacin hydrolysis in PBS 7.4 showed first-order kinetics and rate constant $\mathrm{k}=0.0106$ days $^{-1}$ (Graph 1a and $b)$.

Graph 1. Indomethacin hydrolysis kinetics in PBS 7.4 at $25^{\circ} \mathrm{C}$ a) fit to zero order kinetics $\left(r^{2}=0.9873\right)$, b) fit to first order kinetics $\left(r^{2}=0.9973\right)$ and at $37^{\circ} \mathrm{C}$ c) fit to zero order kinetics $\left.\left(r^{2}=1\right), \mathbf{d}\right)$ fit to first order kinetics $\left(r^{2}=1\right)$

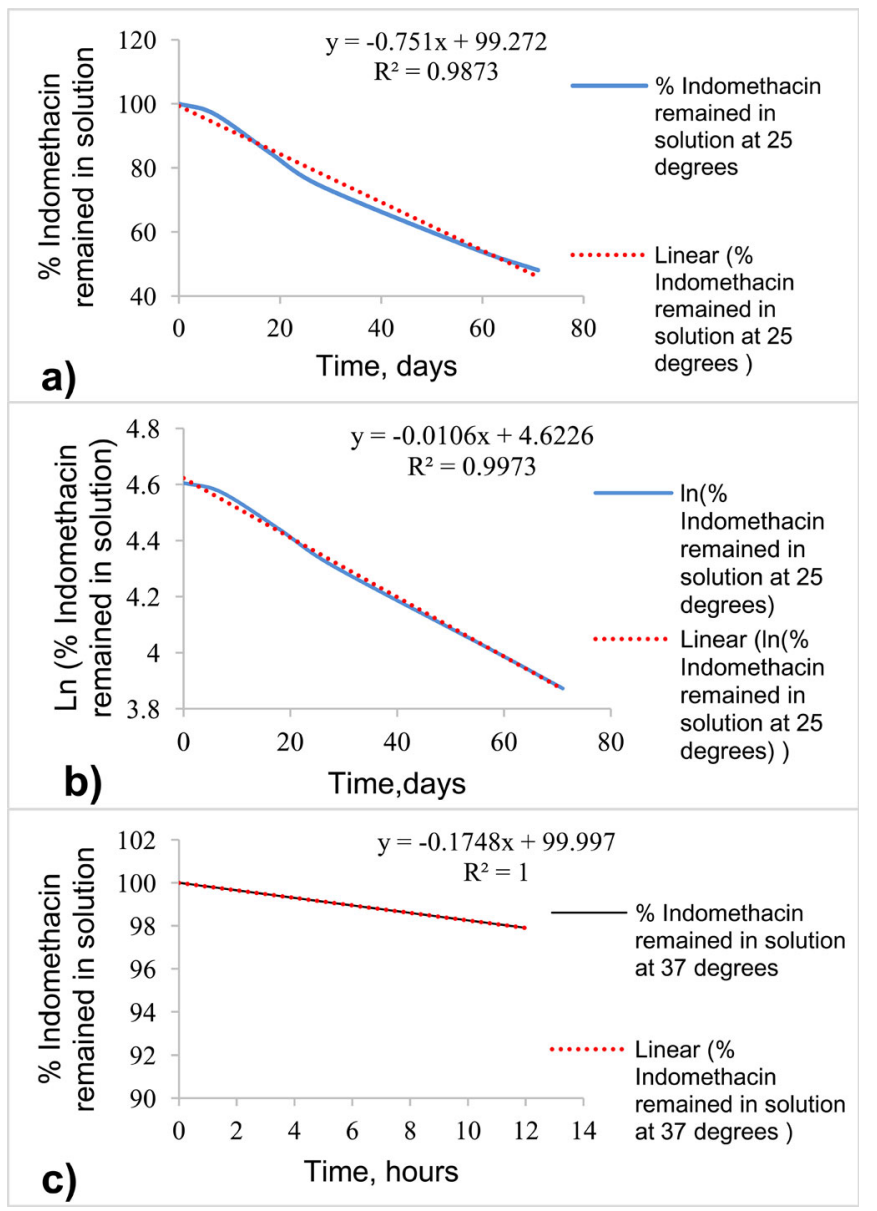

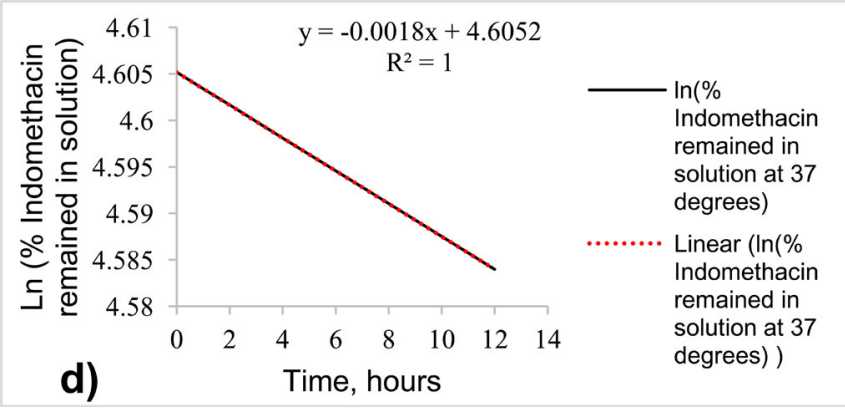

Indomethacin stability in PBS 7.4 at $37 \pm 0.5^{\circ} \mathrm{C}$

Indomethacin degradation rate under dissolution test's conditions is presented on Graph 1c and d. Drug degradation rate constant was found to be $\mathrm{k}=0.0018$ hours $^{-1}$ (or $\mathrm{k}=$ 0.0432 days $\left.^{-1}\right)$. In correlation with these results, the maximum expected drug loss \% due to amide hydrolysis in the receptor media at each sampling time was calculated and presented in Table 2.

Table 2. Maximum expected drug loss \% due to hydrolysis in the receptor media during drug dissolution and permeation tests

\begin{tabular}{cc}
\hline Sampling time, $\mathrm{h}$ & Maximum drug loss, $\%$ \\
\hline 0,5 & 0.09 \\
1 & 0.18 \\
2 & 0.35 \\
4 & 0.71 \\
6 & 1.05 \\
8 & 1.40 \\
12 & 2.10 \\
\hline
\end{tabular}

Physical stability of test formulations

Samples from IG1 stored at 25 and $5^{\circ} \mathrm{C}$ showed formation of a solid phase and sediment on day 1 and 7, respectively (Figure 1). The sample of IG2 stored at room temperature showed phase separation (resembling syneresis) on the first month (Figure 2), whereas for the sample at $5^{\circ} \mathrm{C}$ no visible changes in the period of 3 months were observed. Sample IG3 started to show discoloration after the second month, which we devote to the extensive drug loss, confirmed by the chemical stability test (Figure 3). All other samples exhibited sustained physical stability for the period of the study at both temperatures. 
Fig. 1. Phase separation and sedimentation observed in formulation IG1

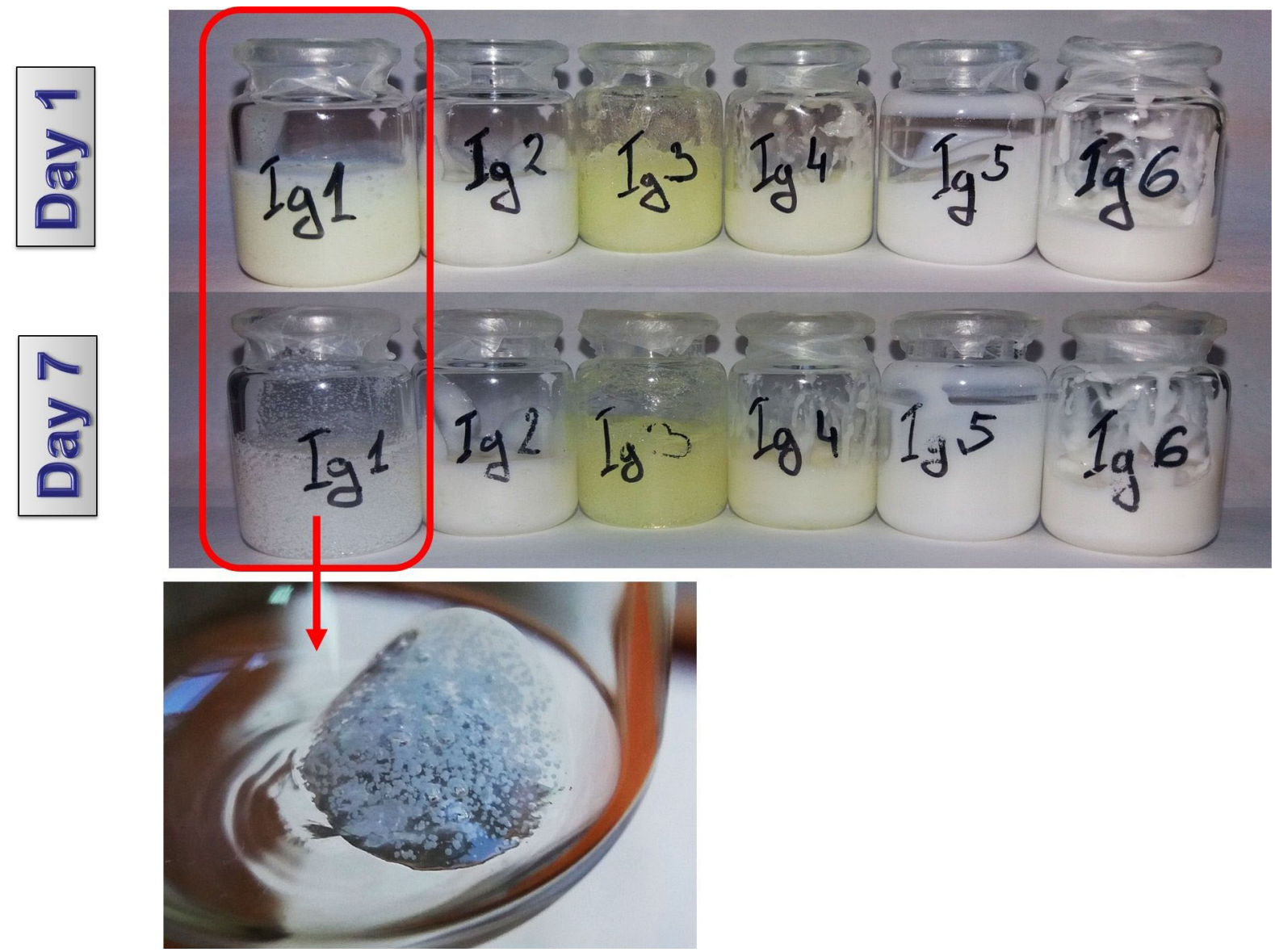

Fig. 2. Phase separation and sedimentation observed in the sample of IG2 stored at $25^{\circ} \mathrm{C}$

Fig. 3. Discoloration of sample IG3
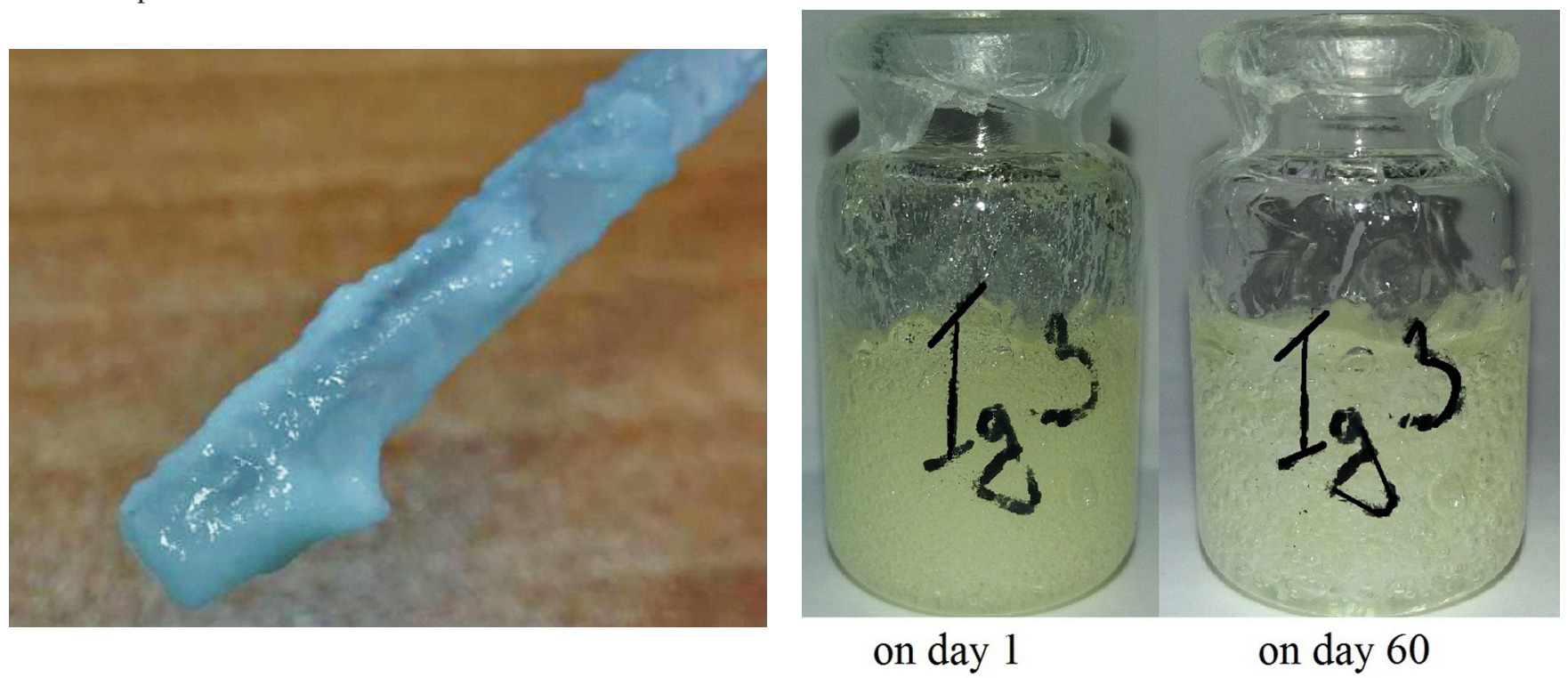

on day 60

Chemical stability of test formulations

All emulgel formulations exhibited good chemical stability and a slower rate of drug decomposition compared to corresponding hydrogels at both temperatures. Among the gelling agents, Poloxamer $40720 \%$ showed the highest chemical preservation potential. Results for Indomethacin 
hydrolysis kinetics in all samples at both temperatures (except IG1, which failed the physical stability test), as well as a prediction for shelf life, are presented on Graph $2 \mathrm{a}$ and $\mathrm{b}$ and Table 3. In correlation with the drug decomposition data in PBS 7.4, degradation rate in gels was also found to fol- low first order kinetics. In this regard, T90\% (Shelf life of gel $=\mathrm{T}_{90 \%}$, - the time for which Indomethacin content drops to $90 \%)$ was calculated as:

$\mathrm{T}_{90 \%}=0.104 / \mathrm{k}^{\prime}$,

Where $\mathrm{k}^{\prime}$ is the first order rate constant of hydrolysis.

Graph. 2. Drug decomposition rate in test formulations at a) $5^{\circ} \mathrm{C}$ and b) $25^{\circ} \mathrm{C}$
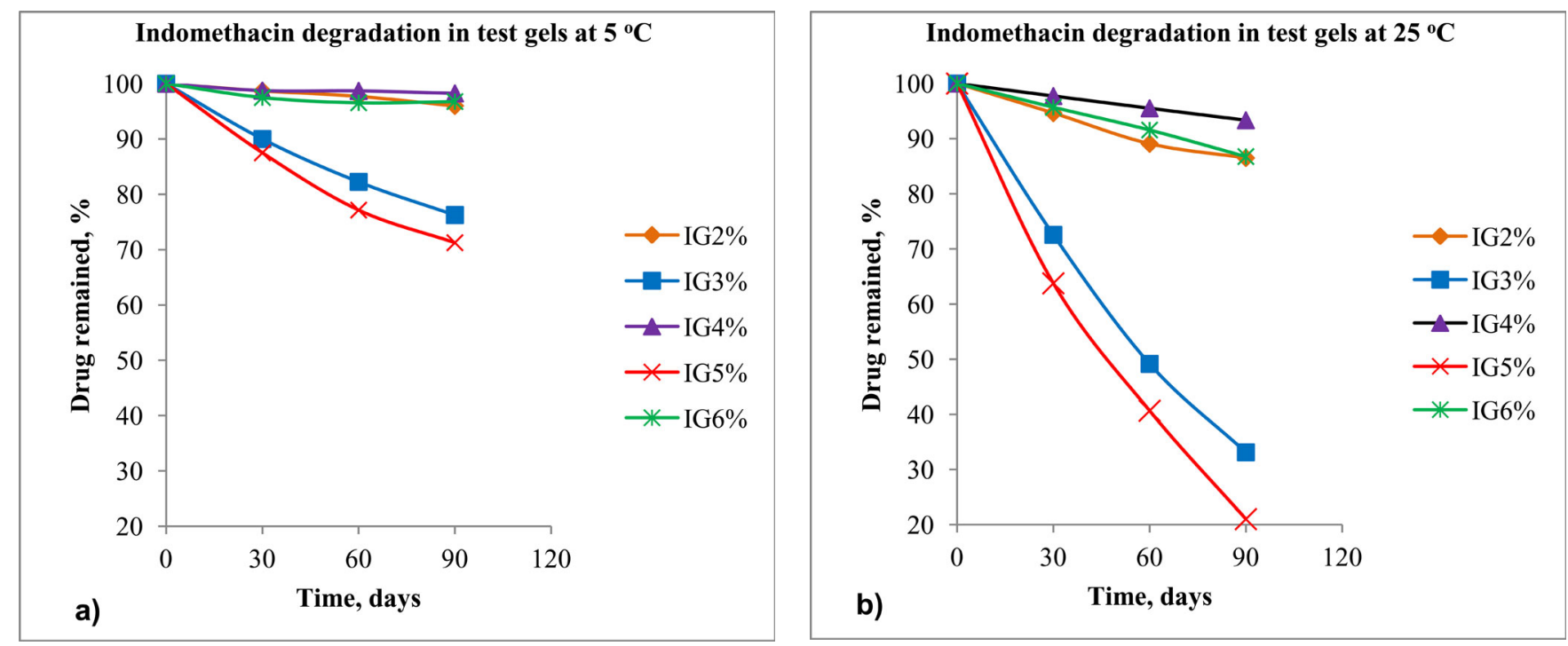

Table 3. Degradation rate in test gels and prediction of shelf life

\begin{tabular}{|c|c|c|c|}
\hline Formulation & $\begin{array}{c}\text { First order hydrolysis } \\
\text { rate constant } \mathrm{k}^{\prime} \text { at } 25^{\circ} \mathrm{C} \text {, } \\
\text { days }^{-1} .10^{2}\end{array}$ & $\begin{array}{c}\text { First order hydrolysis } \\
\text { rate constant } \mathrm{k}^{\prime} \text { at } 5^{\circ} \mathrm{C}, \\
\text { days }^{-1} \cdot \mathbf{1 0}^{2}\end{array}$ & $\begin{array}{c}\text { Prediction for shelf life } \\
\left(\mathrm{T}_{90 \%}\right) \text { if formulation is } \\
\text { stored at } 5^{\circ} \mathrm{C} \text {, days }\end{array}$ \\
\hline IG 2 & 0.164 & 0.040 & 260 \\
\hline IG 3 & 1.230 & 0.300 & 35 \\
\hline IG 4 & 0.080 & 0.020 & 520 \\
\hline IG 5 & 1.539 & 0.380 & 27 \\
\hline IG 6 & 0.160 & 0.040 & 260 \\
\hline
\end{tabular}

Indomethacin was found to be slightly soluble in PBS 7.4 according to the European Pharmacopoeia classification at both temperatures tested $-1.15 \mathrm{mg}^{-\mathrm{ml}^{-1}}$ at $25 \pm 0.5^{\circ} \mathrm{C}$ and $3.17 \mathrm{mg} \cdot \mathrm{ml}^{-1}$ at $37 \pm 0.5^{\circ} \mathrm{C}$.

According to these results, the requirement for "sink" conditions during drug release tests is met, as the drug in donor compartment represents $1 \%$ of dosage form applied $(2.0 \mathrm{mg})$ and receptor media volume is $8.0 \mathrm{ml}$. Even if $100 \%$ drug release occurs (which is practically impossible), maximum concentration in release media will be $0.25 \mathrm{mg} \cdot \mathrm{ml}^{-1}$, which is nearly 13 times lower than the saturation point for the test temperature $\left(37 \pm 0.5^{\circ} \mathrm{C}\right)$.

Drug release and drug release kinetics

Drug release profiles of all test formulations (except IG1, which failed the physical stability test), including USP standard Indomethacin gel and Indextol, are presented on Graph 3. Drug release data was fitted to zero-order, firstorder, Higuchi and Korsmeyer-Peppas models and regres- sion coefficients and kinetic parameters are shown in Table 4. As USP standard Indomethacin gel did not show any drug release in 12 hours, it was not further subjected to permeation study.

Graph. 3. In vitro drug release from Indomethacin semisolid formulations

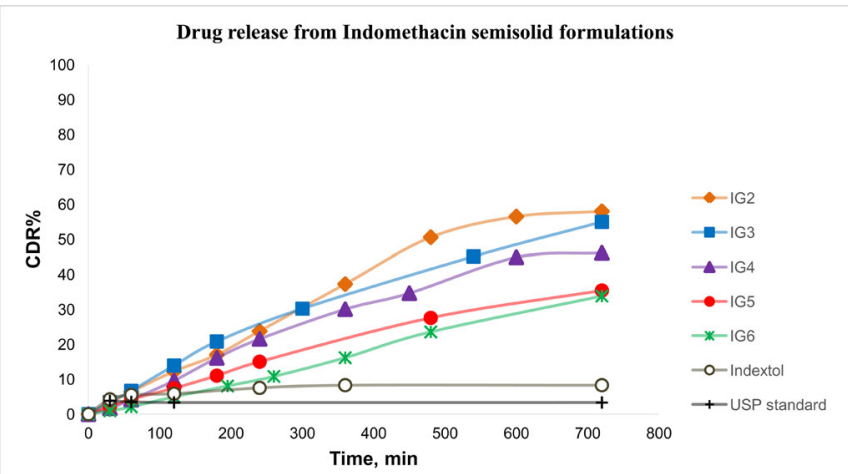


Table 4. Drug release kinetics data

\begin{tabular}{|c|c|c|c|c|c|c|c|c|c|}
\hline \multirow{2}{*}{$\begin{array}{l}\text { Formulation } \\
\text { code }\end{array}$} & \multicolumn{2}{|c|}{$\begin{array}{c}\text { Zero-order } \\
\text { kinetics }\end{array}$} & \multicolumn{2}{|c|}{$\begin{array}{l}\text { First order } \\
\text { kinetics }\end{array}$} & \multicolumn{2}{|c|}{$\begin{array}{l}\text { Higuchi } \\
\text { kinetics }\end{array}$} & \multicolumn{3}{|c|}{$\begin{array}{c}\text { Korsmeyer-Peppas } \\
\text { kinetics }\end{array}$} \\
\hline & $\mathbf{R}^{2}$ & $\mathrm{k}_{0}, \% \cdot \mathrm{min}^{-1}$ & $\mathbf{R}^{2}$ & $\mathbf{k}_{1}, \min ^{-1}$ & $\mathbf{R}^{2}$ & $\mathrm{k}_{2}, \% \cdot \mathrm{min}^{-0,5}$ & $\mathbf{R}^{2}$ & $\mathbf{k}_{3}, \% \cdot \mathrm{min}^{-\mathrm{n}}$ & n \\
\hline IG2 & 0.9939 & 0.1044 & 0.9896 & 0.00138 & 0.9685 & 2.8425 & 0.9981 & 0.114 & 0.9795 \\
\hline IG3 & 0.9785 & 0.0762 & 0.9978 & 0.00115 & 0.9973 & 2.4572 & 0.9911 & 0.194 & 0.8757 \\
\hline IG4 & 0.9906 & 0.0811 & 0.9978 & 0.00092 & 0.9894 & 2.1941 & 0.9895 & 0.068 & 1.1014 \\
\hline IG5 & 0.9872 & 0.0502 & 0.9958 & 0.00069 & 0.9856 & 1.6206 & 0.9976 & 0.105 & 0.8951 \\
\hline IG6 & 0.9967 & 0.0483 & 0.9911 & 0.00046 & 0.9485 & 1.324 & 0.999 & 0.022 & 1.1272 \\
\hline Indextol & 0.5231 & 0.0083 & 0.5534 & 0.00001 & 0.8488 & 0.1943 & 0.9523 & 2.129 & 0.2555 \\
\hline
\end{tabular}
tissue

Drug permeation and drug deposition in mucosal Indomethacin formulation, except IG1 (failed the physical along with the predicted $\mathrm{C}_{\mathrm{ss}}$ and drug deposition in mucosa data, obtained by methods I and II. This was done for each stability test) and USP standard Indomethacin (did not show drug release through an artificial membrane, therefore was considered not proper for mucosal application).

Table 5. Permeation parameters, $\mathrm{C}_{\mathrm{ss}}$ prediction and drug deposition

\begin{tabular}{|c|c|c|c|c|c|c|c|c|c|}
\hline \multirow[t]{2}{*}{ Formulation } & \multicolumn{2}{|l|}{ Flux } & \multirow{2}{*}{$\begin{array}{c}\mathrm{Kp}, \mathrm{cm} \mathrm{h}^{-1} \text {. } \\
10^{2}\end{array}$} & \multirow{2}{*}{$\begin{array}{c}\text { P.D.10 } \\
\text { cm }^{2} \cdot \mathbf{h}^{-1}\end{array}$} & \multirow[t]{2}{*}{$\mathbf{T}_{\mathbf{L}}, \mathbf{h}$} & \multicolumn{2}{|c|}{$\begin{array}{c}\text { Css prediction, } \\
\mu \mathrm{g} . \mathrm{I}^{-1}\end{array}$} & \multicolumn{2}{|c|}{$\begin{array}{c}\text { Drug deposition in } \\
\text { mucosa, } \text { mg.cm }^{-3}\end{array}$} \\
\hline & Jss $\mu$ g.cm-2 ${ }^{-2} h^{-1}$ & $\mathbf{R}^{2}$ & & & & from & to & Method I & Method II \\
\hline IG2 & 10.55 & 0.995 & 0.960 & 0.154 & 0.88 & 40.19 & 100.49 & 1.748 & 0.140 \\
\hline IG3 & 13.20 & 0.989 & 0.161 & 0.026 & 0.99 & 50.29 & 125.71 & 1.656 & 1.888 \\
\hline IG4 & 7.79 & 0.996 & 0.079 & 0.013 & 0.86 & 29.69 & 74.24 & 2.107 & 2.762 \\
\hline IG5 & 4.31 & 0.982 & 0.575 & 0.092 & 2.02 & 16.42 & 41.05 & 0.792 & 1.226 \\
\hline IG6 & 3.87 & 0.960 & 0.403 & 0.065 & 4.85 & 14.75 & 36.87 & 0.381 & 0,850 \\
\hline Indextol & 5.28 & 0.996 & 0.528 & 0.085 & 3.06 & 20.13 & 50.33 & 0.758 & $-*$ \\
\hline
\end{tabular}

*Method II was not applied because the dosage form's vehicle is insoluble in PBS 7,4

$\mathrm{J}_{\mathrm{ss}}=\mathrm{K}_{\mathrm{p}} . \Delta \mathrm{C} ; \boldsymbol{\Delta C}=\mathrm{C}_{\mathrm{d}}-\mathrm{C}_{\mathrm{r}}$, in steady state $\boldsymbol{\Delta C} \approx \mathrm{C}_{\mathrm{d}}$, thus $\mathrm{K}_{\mathrm{p}} \approx \mathrm{J}_{\mathrm{ss}} / \mathrm{C}_{\mathrm{d}} ; \mathrm{K}_{\mathrm{p}}=\mathrm{P} . \mathrm{D} / \mathrm{h}$, where $\mathbf{J}_{\mathrm{ss}}$ issteady-state flux, $\mathrm{K}_{\mathrm{p}}-$ permeability coefficient, $\mathrm{P}$ - partition coefficient, D - diffusion constant, $\mathbf{\Delta C}$ - concentration gradient, $\mathrm{C}_{\mathrm{d}}-$ initial drug concentration in gel, $\mathrm{C}_{\mathrm{r}}$ - concentration in receptor media, $\mathrm{T}_{\mathrm{L}}$ - lag time, $\mathrm{C}_{\mathrm{ss}}-$ steady-state plasma concentration

\section{DISCUSSION}

All emulgels exhibited greater chemical stability than corresponding hydrogels, and if the gelling agent is Methylcellulose, the emulgel formulation was also found to benefit the physical stability. This observation meets our initial expectation, that even when Indomethacin exists in the outer phase of an o/w emulsion before inclusion in the gel, the increased viscosity of the drug dispersion originating from the emulsified oil, will benefit the drug behavior in a semi-solid state.

Longest product's shelf life -1.5 years - was predicted for formulation IG4 - Indomethacin $1 \%$ emulgel prepared with gelling agent Poloxamer 407. An explanation for this observation might be sought in the solubilizing capacity of Poloxamer 407, for the micelles may incorporate the drug and respectively serve as a "shield" against its degradation.

Emulgels showed about $10 \%$ lower CDR\% in 12 hours compared to corresponding hydrogels, which can be interpreted in favor of a local action, rather than systemic. All release profiles were found to be in good correlation with the first and zero order release kinetics. This, in correlation with the high regression coefficients $(>0.990)$ for KorsmeyerPeppas model and release exponent values $(n>0.89)$, testifies for the complex mechanism of drug release - swelling and relaxation stresses, as well as diffusion, contribute to the drug release process.

None of the formulated dosage forms can be considered for systemic effect via rectal administration since we estimated the hypothetical plasma concentration after application on $40 \mathrm{~cm}^{2}$ mucosa to be nearly four times lower than the therapeutic concentration (highest predicted value $125,71 \mu \mathrm{g} . \mathrm{l}^{-1}$, therapeutic concentration $\left.>500 \mu \mathrm{g} . \mathrm{l}^{-1}\right)$. However, if the local effect is targeted, the most promising formulation would be IG4 - Indomethacin 1\% Poloxamer 407 emulgel, which showed the least potential for systemic side effects in combination with the highest drug deposition in the mucosa.

A remark should be made regarding physiological $\mathrm{pH}$ on mucosal surface. As our prognosis was done for the rectal route of administration, we selected a $\mathrm{pH}$ value for the in 
vitro tests at 7.4 (corresponds to the physiological $\mathrm{pH}$ in rectum). However, some pathological processes may lead to a decrease in $\mathrm{pH}$ and by that affect the drug's dissolution potency, ionization and permeation. Good in vitro - in vivo correlation is expected only if $\mathrm{pH}$ in rectum is close to its physiological value - about 7.4. Otherwise, the results from this study should be only taken as comparative, representing the difference between different semi-solid hydrogel- and emulgel vehicles.

\section{CONCLUSIONS AND FURTHER STUDIES}

The inclusion of Indomethacin in gels via o/w emulsion eloquently benefits the drug's and dosage form's stability, as well as the product's therapeutical and safety potential if a local effect is aimed. Even if Poloxamer 407, according to our results, stands out as the most proper gelling agent for Indomethacin gel, it will be interesting to follow the same experimental parameters (chemical and physical stability, drug release and permeation potential) in emulgels obtained with combined gelling agent (for example $10 \%$ Poloxamer $+1 \%$ Methylcellulose or other adhesive polymer). We consider this further experiment valuable because Poloxamer is a thermosensitive polymer and this can be an advantage for application, but it does not possess mucoadhesive properties, which is also important for mucosally administrated dosage forms. Furthermore, it is important to investigate more thoroughly some physicochemical properties of our test formulations (as $\mathrm{pH}$ reaction, viscosity, rheological parameters, mucoadhesion and mucosal retention time) which may contribute to an explanation of the results obtained. We consider such experiments as a part of further studies.

\author{
ABBREVIATIONS \\ BSC - biopharmaceutical classification system \\ API - active pharmaceutical ingredient \\ PES - polyethersulfone \\ PBS - phosphate buffer saline \\ USP - United States Pharmacopeia \\ CDR - cumulative drug released \\ CDP - cumulative drug permeated
}

\section{Remarks}

${ }^{1}$ Information about Indomethacin solubility in PBS 7.4 is provided in the drug release section results.

${ }^{2}$ The drug content in the test formulations was analyzed right before the in vitro and the ex vivo study, so that information about the exact amount of Indomethacin applied at the beginning of each test is available.

3 Other active ingredients in Indextol oromucosal paste - Dexamethasone and Oleandomycin - are not reported to have an absorbance at $\lambda=319$; thus their presence in the release media was not expected to interfere with Indomethacin UV spectrophotometric analysis [24, 25].

${ }^{4}$ We estimated the absorption area for Indomethacin after rectal application to be approximately $40 \mathrm{~cm}^{2}$ based on data in literature [21] and following assumptions: (i) semi-solid dosage form is applied in the lower rectum with applicator 6-7 cm long, which would mean that gel reaches about $4 \mathrm{~cm}$ in length mucosal surface, since applicator must pass through the $2-3 \mathrm{~cm}$ long anal canal first [21]; (ii) the mean inner diameter of rectum is $10 \mathrm{~cm} \mathrm{[21].}$

\section{REFERENCES:}

1. Vranic E, Uzunovic A. Dissolution studies of physical mixtures of indomethacin with alpha- and gammacyclodextrins. Bosn J Basic Med Sci. 2010 Aug;10(3):197-203. [PubMed] [Crossref]

2. El-Leithy ES, Ibrahim HK, Sorour RM. In vitro and in vivo evaluation of Indomethacin nanoemulsion as a transdermal delivery system. Drug Deliv. 2015 Nov;22(8):1010-1017. [PubMed] [Crossref]

3. Czajkowska-Kosnik A, Sznitowska M. Solubility of ocular therapeutic agents in self-emulsifying oils. I. Self-emulsifying oils for ocular drug delivery: solubility of indomethacin, aciclovir, and hydrocortisone. Acta Pol Pharm. 2009 Nov-Dec;66(6): 709-13. [PubMed]

4. Karasulu HY, Sanal ZE, Sözer S, Güneri T, Ertan G. Permeation Studies of Indomethacin from Different Emul- sions for Nasal Delivery and Their Possible Anti-Inflammatory Effects. AAPS Pharm Sci Tech. 2008; 9(2):3428. [PubMed] [Crossref]

5. Dadwal M, Mittal P, Ranal S. Formulation Development And Evaluation Of Indomethacin Emulgel. IJPRD. 2014 Jan;5(11):081-88.

6. Mulye SP, Wadkar KA, Kondawar MS. Formulation development and evaluation of Indomethacin emulgel. Der Pharmacia Sinica. 2013; 4(5):31-45.

7. Kusuma R, Samba Siva Rao A. Formulation, Development, and Evaluation of Indomethacin Emulgel Using Pregelatinized Starch from Ipomoea batata Tubers. Asian J Pharm. 2015 Oct-Dec;9(4):43-50.

8. Krzek J, Starek M. Simultaneous Densitometric Determination of Indomethacin and Its Degradation Products, 4-Chlorobenzoic Acid and 5-
Methoxy-2-Methyl-3-Indoleacetic Acidin Pharmaceutical Preparations.J. AOAC Int. 2001 Nov-Dec;84 (6):170307. [PubMed]

9. Kougioumtzoglou A, Peikova L, Georgieva M, Zlatkov A. Evaluation of the Stability of Indomethacin Substance Under a Model of Physiological Conditions Using Modified and Validated RP-HPLC Method. Pharmavia. 2015; 62 (2):10-17.

10. Temussi F, Cermola F, Dellagreca M, Iesce MR, Passananti M, Previtera L, et al. Determination of photostability and photodegradation products of indomethacin in aqueous media. J Pharm Biomed Anal. 2011 Dec;56(4):678-83. [PubMed] [Crossref]

11. El-Badry M, Fetih G, Fathy M. Improvement of solubility and dissolution rate of indomethacin by solid dispersions in Gelucire 50/13 and 
PEG4000. Saudi Pharm J. 2009 Jul;17(3): 217-25. [PubMed] [Crossref] 12. Comer J, Judge S, Matthews D, Towes L, Falcone B, Goodman J, et al. The intrinsic aqueous solubility of indomethacin. ADMET DMPK. 2014 Apr;2(1):18-32. [Crossref]

13. Saeedi M, Akbaria J, MortezaSemnanib K, Enayati-Farda R, SarReshteh-dara S, Soleymania A. Enhancement of Dissolution Rate of Indomethacin Using Liquisolid Compacts. Iran J Pharm Res. 2011 Winter;10 (1):25-34. [PubMed]

14. Casas M, Ferrero C, JiménezCastellanos $M^{a} R$. Graft tapioca starch copolymers as novel excipients for controlled-release matrix tablets. Carbohydr Polym. 2010 Mar;80(1): 71-77. [Crossref]

15. Singhvi G, Singh M. Review: In-Vitro Drug Release Characterization Models. Int J Pharm Sci Res. 2011 Jan- Mar;2(1):77-84.

16. Cojocaru V, Ranetti A L, Hinescu L G, Ionescu M, Cosmescu C, Po'toarcã AG, et al. Formulation And Evaluation Of In Vitro Release Kinetics Of $\mathrm{NA}_{3} \mathrm{CADTPA}$ Decorporation
Agent Embedded In MicroemulsionBased Gel Formulation For Topical Delivery. Farmacia. 2015 Sep-Oct; 63(5):656-664.

17. Amores S, Domenech J, Colom H, Calpena A, Clares B, Gimeno A, et al. An improved cryopreservation method for porcine buccal mucosa in ex vivo drug permeation studies using Franz diffusion cells. Eur J Pharm Sci. 2014 Aug 18;60:49-54. [PubMed] [Crossref]

18. Brodin B, Steffansen B, Nielsen C. Passive diffusion of drug substances: the concepts of flux and permeability, Molecular biopharmaceuticals. Pharmaceutical Press. 2009. Chapter 3.2, p. 135-52.

19. Khan S, Gajbhiye C, Singhavi DJ, Yeole P. In situ Gel of Metoprolol Tartrate: Physicochemical Characterization, In vitro Diffusion and Histological Studies. Indian J Pharm Sci. 2012 Nov-Dec;74(6):564-70. [PubMed] [Crossref]

20. Herkenne C, Naik A, Kalia Y, Hadgraft J, Guy R. Ibuprofen Transport into and through Skin from Topical Formulations: In Vitro -In Vivo Com- parison. J Investig Dermatol. 2007 Jan;127(1):135-42.[PubMed] [Crossref]

21. Vankov V, Ovcharov VL. [Anatomy of the human body]. Arso Sofia. 2016. [inBulgarian]

22. Helleberg L. Clinical Pharmacokinetics of Indomethacin. Clin Pharmacokinet. 1981 Jul-Aug;6(4): 245-58. [PubMed] [Crossref]

23. Alvan G, Orme M, Bertilsson L, Ekstrand R, Palmér L. Pharmacokinetics of indomethacin. Clin Pharmacol Ther. 1975 Sep;18(3):364-73. [PubMed]

24. Shah A, Khan A, Usman M, Qureshl R, Siddiq M, Shah S. Thermodynamic Characterization Of Dexamethasone Sodium Phosphate And Its Complex With Dna As Studied By Conductometric And Spectroscopic Techniques. J Chil Chem Soc. 2009 Jun;54(2):134-137. [Crossref]

25. Dzegilenko NB, Vtorova ZE, Korchagin VB. [Quantitative determination of anhydroleandomycin and glycol in oleandomycin phosphate]. Antibiotiki. 1976 Apr;21(4):313-6. [in Russian] [PubMed]

Please cite this article as: Ivanova NA, Stefanova TS, Iliev IR, Stoyanov GS, Bratoeva KZ. Kinetic modeling on amide hydrolysis, drug release and mucosal permeation of Indomethacin in the composition of selected semisolid vehicles. $J$ of IMAB. 2018 Oct-Dec;24(4):2303-2312. DOI: https://doi.org/10.5272/jimab.2018244.2303

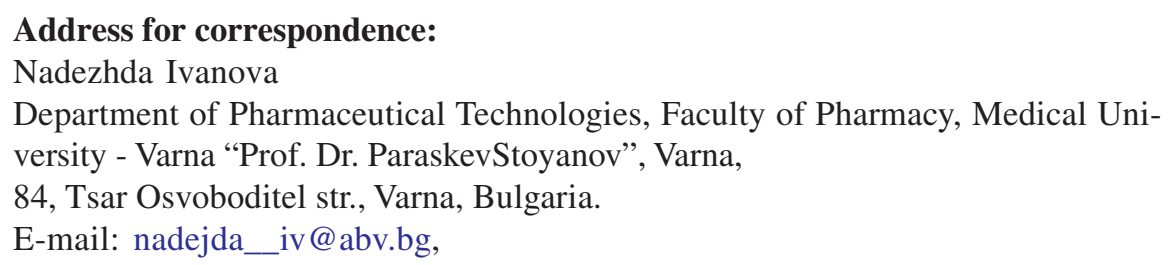

